\title{
Caracterización molecular de Trichoderma spp. en arveja Pisum sativum L.
}

\author{
Molecular characterizacion of Trichoderma spp. in pea Pisum sativum L.
}

\section{Oscar Eduardo Checa C. ${ }^{1}$; Jessica Andrea Descance V. ${ }^{2}$; Maribel Xiomara Toro C. ${ }^{2}$; Sandra Lorena Álvarez ${ }^{3}$; Claudia Salazar G ${ }^{4}$.}

1 Ingeniero Agrónomo, Ph.D. Universidad de Nariño.Colombia, cicagrarias@hotmail.com.

2 Ingenieras Agronómas. Universidad de Nariño. Colombia, masyemmanueltoro@hotmail.com

3 Bióloga, M.Sc. Universidad de Nariño. Colombia.

4 M.Sc. Fitotecnia. Universidad de Nariño. Colombia.

Citar: CHECA, 0.; DESCANSE, J.; TORO, M., ALVAREZ, S.; SALAZAR, C. 2015. Caracterización molecular de Trichoderma spp. en arveja Pisum sativum L. Rev. Cienc. Agr. 32(2):3 - 12

Fecha de recepción: Junio 6 de 2015

Fecha de aceptación: Octubre 10 de 2015

\section{RESUMEN}

Mediante marcadores RAPDs se determinó la variabilidad genética de aislamientos de Tricoderma spp. encontrándose alto polimorfismo con los primeros OPA 03, OPD 05, OPA 01 y 0PB 01. La variación molecular observada fue baja (26\%) entre las poblaciones de Trichoderma spp. identificadas por su origen geográfico como Ipiales, Pupiales y Gualmatán. En contraste la variación dentro de las poblaciones fue alta, superando el 70\%. Las especies de Trichoderma spp. encontradas no mostraron una relación con el origen geográfico. Los aislados se agruparon con base en la diversidad genética de Jaccard. El rango de distancia genética entre los distintos aislamientos estuvo entre 0,37 y 1,42. La especie más frecuente fue T. harzianum que mostró alta variación al estar presente en todos los agrupamientos.

Palabras clave: Diversidad genética, hongo benéfico, RAPDs.

\begin{abstract}
The genetic variability of Trichoderma spp isolates was determined through RAPD markers. A high polymorphism was found with primers OPB 01, OPC 01, OPA 03, OPD 05, and OPA 01. The observed molecular variation was
\end{abstract}


low (26\%) among Trichoderma spp populations, which were identified by their geographical origin as Ipiales, Pupiales, and Gualmatán. In contrast, variation within populations was high, exceeding $70 \%$. The Trichoderma spp. species showed no relationship with their geographical origin. The isolates were grouped based on Jaccard's genetic diversity. The range of genetic distance between the different isolates was between 0.37 and 1.42 . The most frequent species was T. harzianum, which showed a high variation in all clusters.

Key words: Genetic diversity, beneficial fungus, RAPDs.

\section{INTRODUCCIÓN}

Las pudriciones de raíz se encuentran entre las más importantes fitopatologías que mundialmente causan significativas pérdidas económicas en diferentes cultivos agrícolas. Aunque los productos químicos sintéticos son aún la principal herramienta de control para estas enfermedades, los agentes biológicos son una manera efectiva para proporcionar un control más rápido y más seguro, además pueden ser incluidos dentro del control integrado de plagas y enfermedades (Verma et al., 2007).

La principal estrategia para el biocontrol, ha sido la identificación de microorganismos del suelo que sean antagonistas efectivos, estrategia que ya cuenta con resultados exitosos (Alabouvette y Steinberg, 2006; Sánchez et al., 2008). Trichoderma spp. es un organismo de vida libre en suelos y ecosistemas de raíz, donde se pueden observar interacciones complejas entre la planta huésped, los patógenos y diversos factores del ambiente (Harman, 2006; Woo et al., 2006). Éste es un hongo fácil de aislar en medios de cultivo naturales o semisintéticos (Rey et al., 2000).

Diversas especies de Trichoderma spp., son utilizadas en la agricultura para el manejo de fitopatógenos, ya que limitan el desarrollo de hongos dañinos como Rhizoctoniasolani, Fusarium oxysporum y Verticillium dahliae (González et al., 2005). Los factores clave, que contribuyen al efecto antagónico de estos organismos son su rápido crecimiento, producción de metabolitos antimicrobianos y sus características fisiológicas, sin embargo, para una adecuada comprensión de las propiedades bioquímicas, genéticas y fisiológicas se requiere de la acertada ubicación taxonómica de estos organismos (Kullnig et al., 2001).

La variabilidad de las características morfológicas de las especies de Trichoderma, hace que su clasificación sea difícil, no obstante, con el desarrollo de técnicas moleculares la sistemática de este género ha avanzado sustantivamente en los últimos años y es debido a este avance que la importancia de métodos morfológicos ha disminuido paulatinamente (Kullnig et al., 2001; Kredics et al., 2006). La presente investigación tuvo como objeto caracterizar molecularmente 12 cepas de Trichoderma spp.

\section{MATERIALES Y MÉTODOS}

Los bioensayos se realizaron en el laboratorio de sanidad vegetal pertenecientes a la Universidad de Nariño, a una altitud de $2.540 \mathrm{msnm}, 01^{\circ} 12^{\prime} 13^{\prime \prime} \mathrm{LN}$ y 77ํ1'23” L0. El trabajo parte de una colección de cepas nativas de Trichoderma provenientes de los municipios de Gualmatan, Pupiales e Ipiales, identificadas morfológicamente por el programa de biología de la Universidad de Nariño (Tabla 1). 
Tabla 1. Procedencia, fuente e identificación morfológica de los aislamientos colectados en diferentes localidades productoras de arveja en Nariño.

\begin{tabular}{cll}
\hline Aislamiento & Localidad & \multicolumn{1}{c}{ Identificación } \\
\hline C1 & Pupiales & T. harzianum \\
C2 & Pupiales & T. harzianum \\
C3 & Pupiales & T. asperellum \\
C4 & Pupiales & T. asperellum \\
C5 & Gualmatán & T. harzianum \\
C6 & Gualmatán & T. longibrachiatum \\
C7 & Gualmatán & T. harzianum \\
C8 & Gualmatán & T. harzianum \\
C9 & Ipiales & T. longibrachiatum \\
C10 & Ipiales & T. harzianum \\
C11 & Ipiales & T. harzianum \\
C12 & Ipiales & T. harzianum \\
\hline
\end{tabular}

\section{Identificación molecular}

\section{Multiplicación del hongo para extracción de} ADN. Aislamientos de Trichoderma se cultivaron durante seis días en medio liquido (200g papa, $20 \mathrm{~g}$ sacarosa, $1000 \mathrm{ml}$ de agua destilada), a temperatura ambiente. Se hicieron seis repeticiones por aislamiento éstos se dejaron crecer diez días. El mi- celio obtenido de cada aislamiento fue secado en cámara de flujo laminar mediante bomba de vacío, posteriormente macerado con nitrógeno líquido y almacenado a $-20^{\circ} \mathrm{C}$ (Figura 1).

Extracción de ADN. La extracción de ADN de los aislamientos de Trichoderma spp. se llevó a cabo en el laboratorio de Biología Molecular de la Universidad de Nariño, empleando el protocolo de extracción directa establecido por Griffith y Shaw (1998).

Empleando el micelio de Trichoderma almacenado, se agregaron $800 \mu \mathrm{L}$ de buffer de extracción CTAB (NaCl1.4M, EDTA pH $8.020 \mathrm{mM}$, Tris $\mathrm{HCl} 100 \mathrm{mM}$ $\mathrm{pH}$ 8.0, CTAB 2\%) agitando en vortex, luego aplicar $1.5 \mu \mathrm{L}$ de Proteinasa k en cada muestra y se incubó a $65^{\circ} \mathrm{C}$ por una hora. Posteriormente, se agregaron $600 \mu \mathrm{L}$ de cloroformo agitando en vortex (10 min), solución que se centrifugó a 17.000 gravedades durante diez minutos de la cual se tomaron $600 \mu \mathrm{L}$ de la fase superior y se transfirieron a un tubo nuevo adicionando 0,6 volúmenes de isopropanol. Posteriormente se dejó en posición vertical a temperatura ambiente durante cinco minutos y se centrifugó a 17.000 gravedades

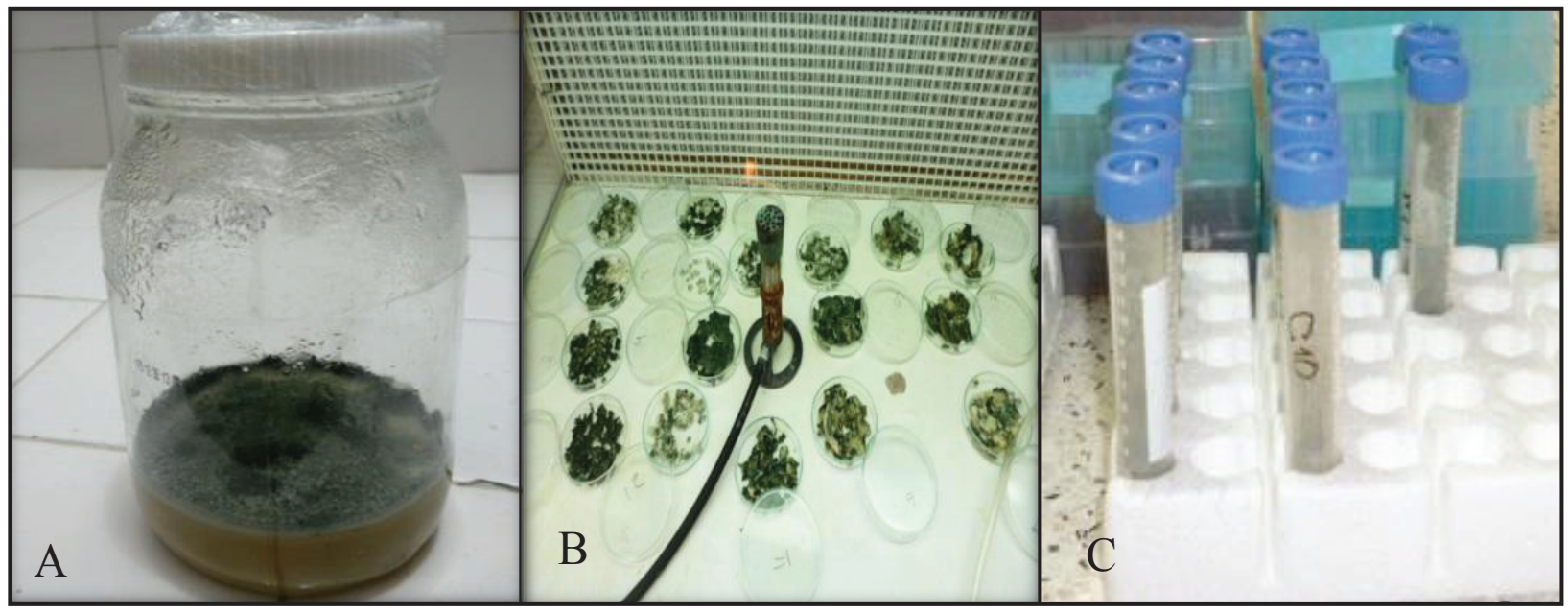

Figura 1. A: Aislamiento de Trichoderma en medio de cultivo liquido, B: Secado de micelio por filtración, C: Micelio macerado con nitrógeno líquido. 
(10 min) eliminando el sobrenadante. El pellet fue lavado con un mililitro de etanol (70\%), se agitó y se dejó a $65^{\circ} \mathrm{C}$ durante 20 minutos, luego se centrifugó a 17.000 gravedades (10 $\mathrm{min}$ ) y se dejó a temperatura ambiente durante el tiempo suficiente para remover cualquier traza de etanol. Finalmente, se resuspendió en $200 \mu \mathrm{L}$ de buffer TE $1 \mathrm{X}$ y se agregaron $3 \mu \mathrm{L}$ de ARNasa $(10 \mathrm{mg} /$ $\mathrm{mL}$ ) dejándose durante dos horas a $37^{\circ} \mathrm{C}$. El ADN obtenido se almacenó a $-20^{\circ} \mathrm{C}$. La integridad del ADN extraído se determinó mediante electroforesis en gel de agarosa al $1 \%$, teñido con $3 \mu \mathrm{L}$ de Bromuro de Etidio $(10 \mathrm{mg} / \mathrm{mL})$.

Análisis de variabilidad genética de Trichoderma spp. mediante marcadores RAPDs. La reacción de los RAPDs se llevó a cabo usando siete oligonucleótidos decaméricos de secuencias al azar (Tabla. 2). Los cebadores se utilizaron en reacciones individuales para la amplificación de 12 aislamientos de Trichoderma spp.

Se amplificó un volumen de $15 \mu \mathrm{L}$ para cada una de las muestras, en cada oligonucleótido se preparó una mezcla con todos los reactivos excepto el ADN, posteriormente se transfirieron $10 \mu \mathrm{L}$ de la mezcla a cada uno de los tubos de PCR, finalmente se agregó $5 \mu \mathrm{L}$ de ADN. Las reacciones de amplificación fueron realizadas en un Termociclador Nyx Technik Amplitronix de serie seis. Para todos los cebadores RAPDs se siguieron las condiciones de amplificación Lardner et al. (1999). No se utilizaron controles positivos. La separación de los productos amplificados se realizó en cámara de electroforesis utilizando geles de agarosa al 2\%, preparados con buffer TBE al 0,5\% y teñidos con $3 \mu \mathrm{L}$ de bromuro de etidio $0,5 \mathrm{mg} / \mathrm{mL}$.

\section{RESULTADOS Y DISCUSIÓN}

\section{Caracterización Molecular}

Extracción de ADN. Se obtuvo ADN de buena calidad. En concentraciones entre 80 y $200 \mathrm{ng}$ siguiendo el protocolo de Griffith y Shaw (1998). Se sembró simultáneamente un juego de seis cepas en la parte superior del gel (C1 a C6) y segundo juego en la parte inferior del gel (C7 a C12) (Figuras 2 y 3$)$.

Tabla 2. Características de los 10 oligonucleótidos utilizados para determinar la variabilidad genética de 12 aislamientos de Trichoderma spp.

\begin{tabular}{ccccc}
\hline Cebador & $\begin{array}{c}\text { Secuencia } \\
(\mathbf{3} \rightarrow \mathbf{5})\end{array}$ & $\begin{array}{c}\text { Peso molecular } \\
\mathbf{g} / \mathbf{m o l}\end{array}$ & $\begin{array}{c}\text { Contenido de } \\
\text { CG } \mathbf{\%}\end{array}$ & $\begin{array}{c}\text { Temperatura } \\
{ }^{\mathbf{0}} \mathbf{C}\end{array}$ \\
\hline OPA 03 & AGT CAG CCA C & 2996,9 & 70,0 & 34,0 \\
OPE 01 & CCC AAG GTC C & 2972,9 & 70,0 & 34,0 \\
OPD 05 & TGA GCG GAC A & 3077,0 & 60,0 & 32,0 \\
OPA 01 & CAG GCC CTT C & 2963,9 & 70,0 & 34,0 \\
OPB 01 & GTT TCG CTC C & 2969,9 & 60,0 & 32,0 \\
OPC 01 & TTC GAG CCA G & 3028,0 & 60,0 & 32,0 \\
OPD 06 & ACC TGA ACG G & 3037,0 & 60,0 & 32,0 \\
\hline
\end{tabular}




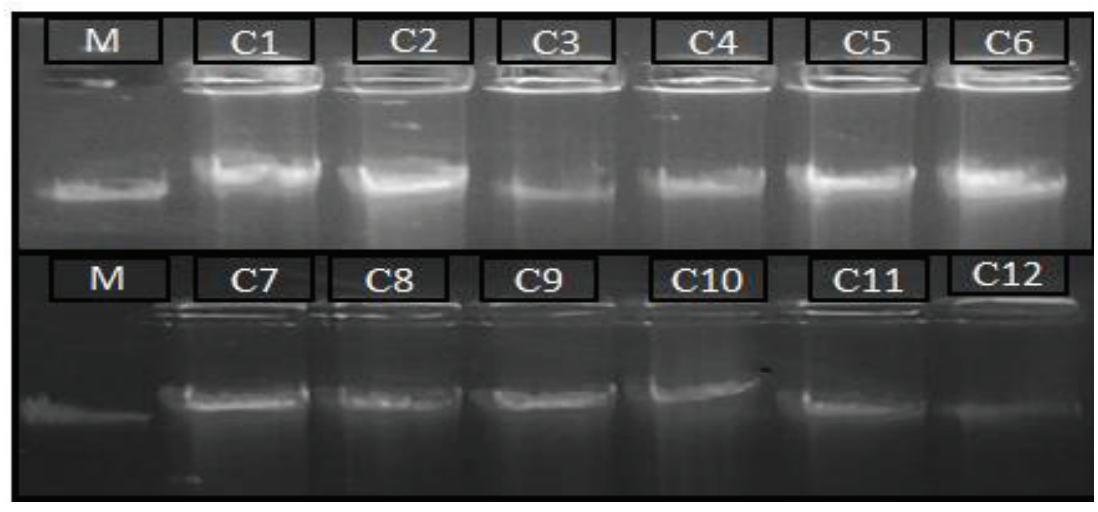

Figura 2. Amplificación de ADN de Trichoderma spp. Obtenido de muestras de rizosfera en arveja de acuerdo al protocolo de Griffith y Shaw (1998). Carriles C1, C2, C5, C7, C8, C10, C11 y C12 de T. harzianum., carriles C3 y C4 de T. asperellum., carrlies C6 y C9 de T. longibrachiatum.

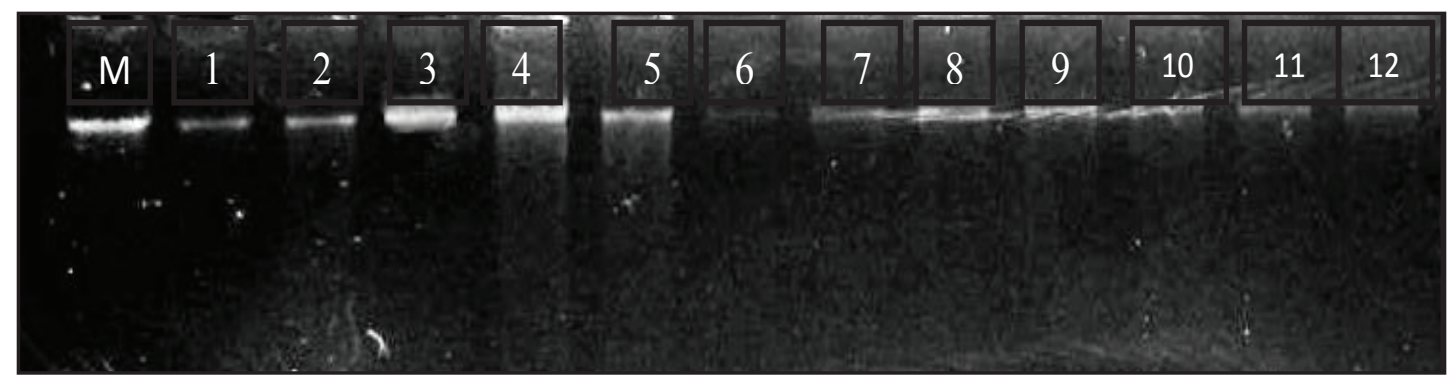

Figura 3. Dilución de ADN de doce aislamientos de Trichoderma en gel de agarosa al 2\%. Carriles 1, 2, 5, 7, 8, 10, 11 y 12 de T. harzianum., carriles 3 y 4 de T. asperellum., carriles 6 y 9 de T. longibrachiatum.

Análisis de la variabilidad mediante marcadores RAPD. Se evaluaron 12 aislamientos de Trichoderma spp. empleando siete cebadores decaméri- cos de secuencias al azar. Los patrones de bandas presentaron diferencias polimórficas, amplificándose 46 fragmentos (Tabla 3).

Tabla 3. Número de loci totales generados con cebadores: OPA 03, OPE 01, OPD 05, OPA 01, OPB 01, OPC 01, 0PD 06 en la caracterización molecular de cepas de Trichoderma.

\begin{tabular}{cccc}
\hline Cebador & Bandas totales (BT) & Bandas polimórficas (BP) & Porcentaje de polimorfismo (\%) \\
\hline OPA 03 & 7 & 6 & 85 \\
OPE 01 & 4 & 3 & 75 \\
OPD 05 & 3 & 3 & 100 \\
OPA 01 & 5 & 4 & 80 \\
OPB 01 & 10 & 9 & 90 \\
OPC 01 & 10 & 5 & 50 \\
OPD 06 & 5 & 3 & 60 \\
\hline TOTAL & 44 & 33 & 77,14 \\
\hline
\end{tabular}


Para el análisis, sólo se consideraron aquellas bandas que fueron capaces de ser distinguibles como presentes o ausentes dadas las condiciones propias de cada gel. La intensidad de las bandas no fue considerada un factor polimórfico de acuerdo a las sugerencias de Luna et al. (2003).

El mayor número de fragmentos amplificados se obtuvo con los cebadores OPB 01 y OPD 05 con nueve y tres bandas polimórficas, mientras que el menor número correspondió a OPC 01 y OPD 06 con cinco y tres bandas polimórficas, el tamaño molecular de los fragmentos osciló entre 100 y 3000 pb, rango esperado debido a las condiciones de reacción de PCR que limitan el tamaño de los fragmentos amplificados entre estos valores (Williams et al., 1990, Luna et al., 2003).

Con el primer cebador OPA 03, amplificaron nueve aislamientos de Trichoderma obteniendo siete bandas con un peso molecular aproximado de 390 a $900 \mathrm{pb}$, de las cuales seis fueron polimórficas para un total de $85 \%$ de polimorfismo (Figura 4).

Con el primer cebador OPD 05, amplificaron siete aislamientos de Trichoderma con tres bandas polimórficas con un peso molecular aproximado entre 330 a $1500 \mathrm{pb}$, encontrándose un polimorfismo del 100\% . (Figura 5).

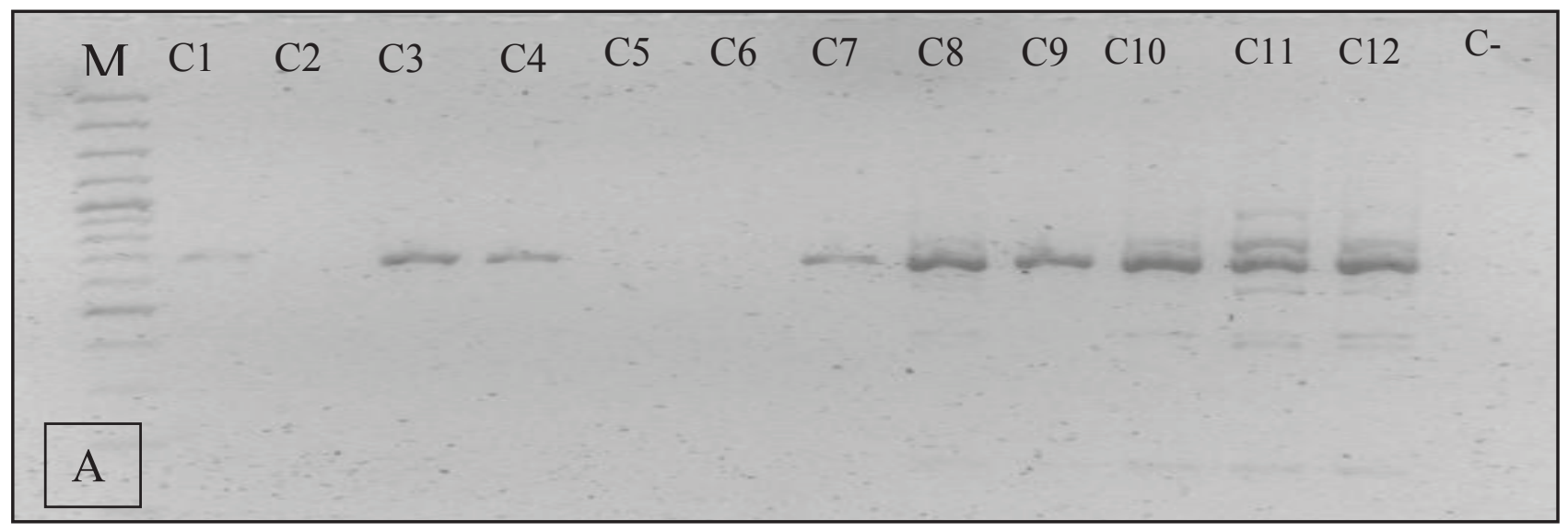

Figura 4. Patrón de bandas de 12 aislamientos de Trichoderma spp. obtenidos del departamento de Nariño mediante RAPDs utilizando el cebador OPA 03; M: ADN Ladder de 100 pb (100-3000pb) C- control negativo.

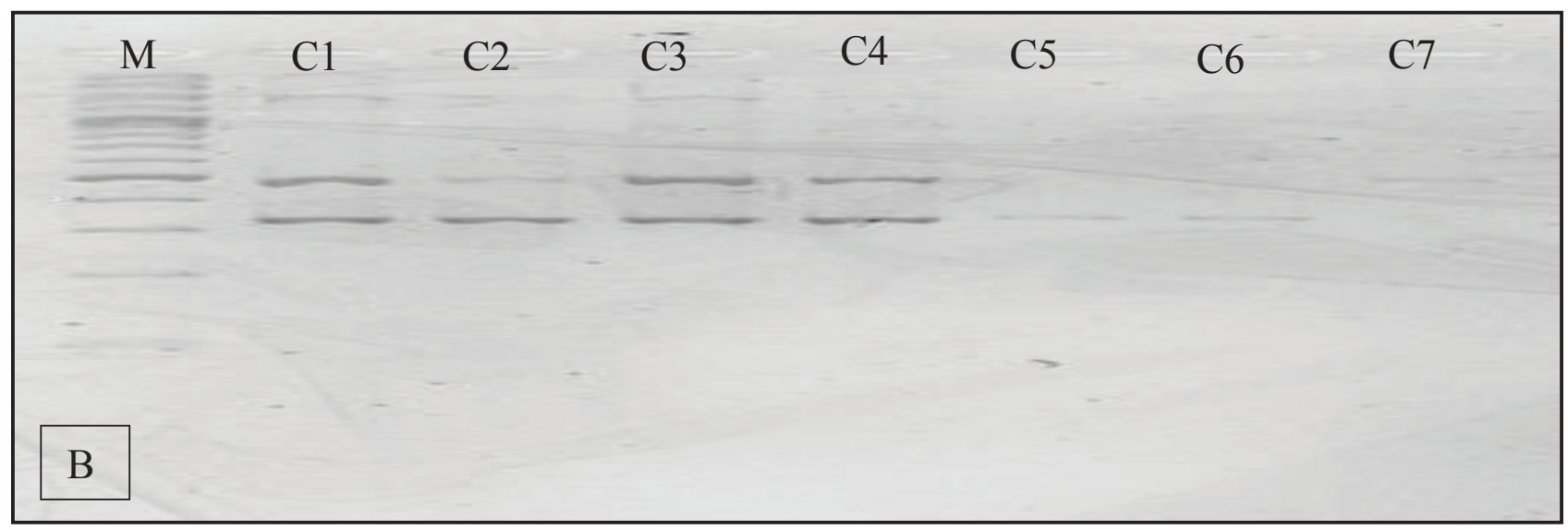

Figura 5. Patrón de bandas para 7 de 12 aislamientos de Trichoderma spp. Obtenidos del departamento de Nariño mediante RAPDs utilizando el cebador OPD 05: M:ADN Ladder de 100pb (100-3000pb). 
Con el cebador OPB 01 (Figura 6). Se obtuvo un total de 10 bandas, con un tamaño aproximado de 300 a 2500 pb, las cuales presentaron el 90\% de polimorfismo ( 9 bandas), se detectó un alto grado de variabilidad entre los aislamientos.

Análisis de varianza molecular. Mediante análisis de varianza molecular se determinó que el 74\% de la diversidad se debe a la variación dentro de las tres poblaciones de Trichoderma spp. estudiadas en comparación con el $26 \%$ correspondiente a la variación entre las tres regiones de estudio (Ipiales, Pupiales y Gualmatán) (Tabla 4). Lo an- terior indica que no existen diferencias importantes atribuibles a la variación entre las localidades donde se obtuvieron los aislamientos que hayan aportado significativamente a la diversidad genética encontrada, por lo tanto, la diversidad es más atribuible a los efectos particulares dentro de cada localidad.

El análisis de diversidad genética a partir de los datos moleculares generados mediante marcadores RAPDs, mostró que Trichoderma spp. es un microorganismo altamente variable desde el punto de vista genético.

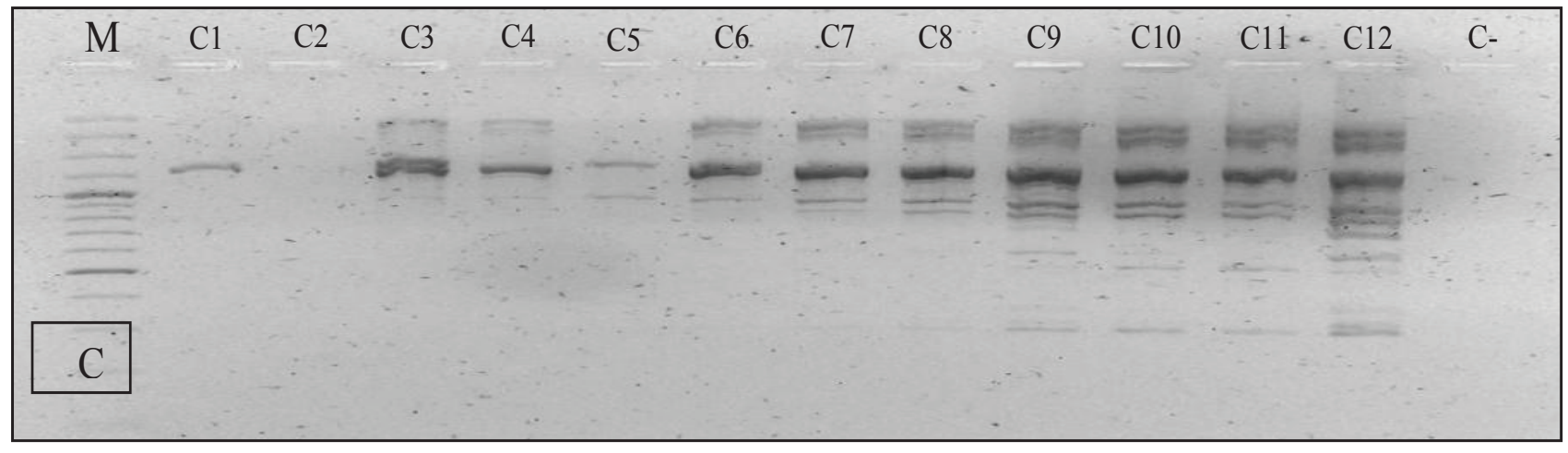

Figura 6. Patrón de bandas de 12 aislamientos de Trichoderma spp. Obtenidos del departamento de Nariño mediante RAPDs utilizando el cebador OPB 01, M: ADN Ladder de 100 pb (100-3000pb) C- Control negativo.

Tabla 4. Análisis de la varianza molecular de tres poblaciones de Trichoderma spp. (Ipiales, Pupiales y Gualmatán - Nariño) evaluadas mediante ADN polimórfico amplificado al azar.

\begin{tabular}{lllll}
\hline \multicolumn{1}{c}{ FV } & SC & $\begin{array}{c}\text { Componentes } \\
\text { de varianza }\end{array}$ & $\begin{array}{c}\text { Variación } \\
\text { porcentual }\end{array}$ & \multicolumn{1}{c}{ P-valor } \\
\hline Entre las poblaciones & 20,667 & 1,507 & 26 & 0,010 \\
Dentro de las poblaciones & 38,750 & 4,306 & $74 \%$ & 0,010 \\
Total & 59,417 & 5,813 & $100 \%$ & \\
Fuente de variación & & & & \\
\hline
\end{tabular}

En el dendograma generado mediante el análisis de agrupamiento UPGMA se observan 3 grupos de cepas bien diferenciados (Figura 7). El primer grupo incluye seis aislamientos de Trichoderma spp. (C1, C3, C4, C5, C6 y C9). Estas cepas morfológica- mente corresponden a tres especies (T. harzianum, Tasperellum, T. longibrachiatum); en el segundo grupo se encuentran las cepas C7, C8, C10, C11 y C12 que corresponden a T. harzianum y el tercer grupo incluye únicamente a la cepa C2 la cual 
presentó un coeficiente de distancia de Jaccard de 1.42, indicando un amplio distanciamiento genético respecto al resto de los aislamientos, de igual manera que el grupo anterior esta especie morfológicamente correspondió a T. harzianum.

En este estudio se encontró alta variabilidad genotípica intraespecífica en Trichoderma, a pesar de estar potencialmente limitado en su capacidad de generar variación debido a su reproducción de tipo asexual. Esta alta variación dentro de las poblaciones puede explicarse debido a la existencia de diferentes mecanismos de generación de variabilidad genética como las mutaciones (de cromosoma, por inserción o eliminación de fragmentos de $\mathrm{ADN}$, o transposones), el flujo de genes en las poblaciones (local o a largas distancias) y la recombinación (sexual o asexual). Este tipo de variación puede ser continua o discontinua. La variación continua se presenta cuando se observa diferencia entre dos extremos de una población de patógenos, pero la diferencia entre los individuos es muy sutil. Por el contrario, la mutación discontinua ocurre cuando la expresión del cambio tiene efectos determinantes (Carlile y Watkinson, 1996).
Al utilizar los marcadores RAPDs no se encontró una relación entre el agrupamiento de los aislamientos con la procedencia de cada uno de ellos, ya que al pertenecer a zonas agroecológicas similares es posible que la variabilidad no haya sido afectada por localidad y en consecuencia no generó cambios importantes en la constitución genética de los aislamientos. El dendrograma permitió establecer que hay variaciones genéticas dentro de la misma especie de Trichoderma, lo cual fue observable de manera especial en T. harzianum que está presente en todos los aislamientos que hacen parte del segundo agrupamiento, también se encuentra presente en dos de los seis aislamientos del segundo grupo y existe un aislamiento de esta misma especie (T. harzianum) que constituyó un grupo diferente. Los marcadores RAPDs empleados fueron útiles para diferenciar y agrupar a cinco de los ocho aislamientos de $T$. harzianum, sin embargo, los tres aislamientos restantes de esta especie que hicieron parte de los otros dos agrupamientos, indican que dentro de $T$. harzianum hay variabilidad que permite a algunos de sus aislamientos acercarse más a otras especies de Trichoderma spp. desde el punto de vista de la constitución de su genoma, tal como se observa en el primer agrupamiento.

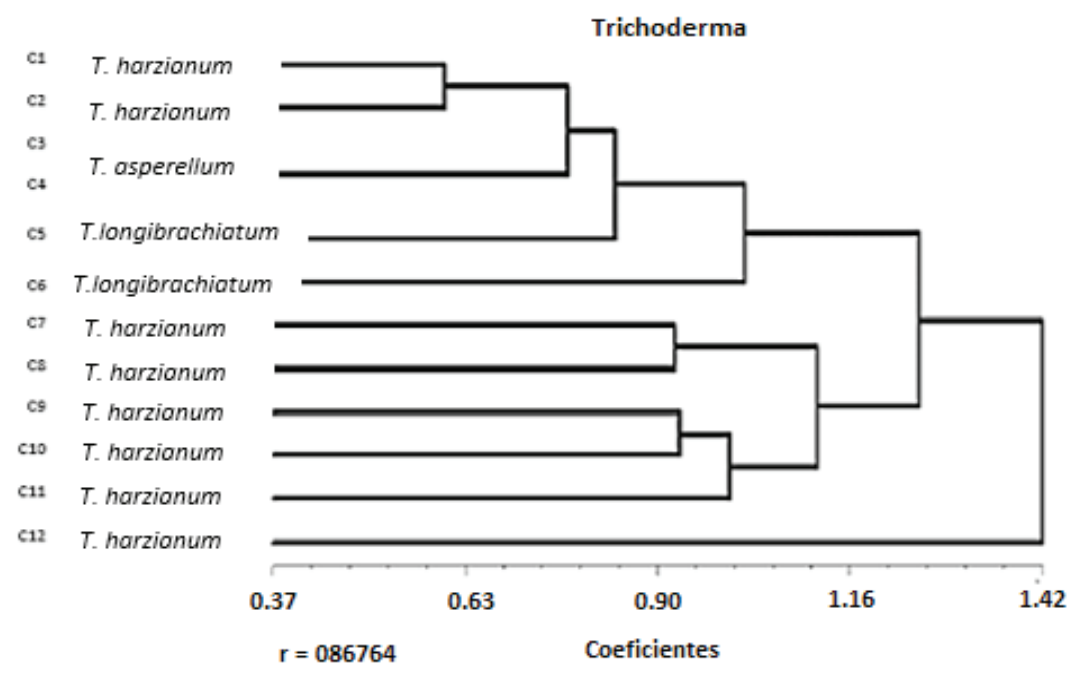

Figura 7. Dendograma obtenido mediante algoritmo de UPGMA de los coeficientes distancia (1-S de Jaccard) con datos de RAPDs en 12 aislados de Trichoderma spp. 
El hecho de que aislamientos T. harzianum, T.asperellum y T. longibrachiatum se encuentren en el mismo agrupamiento, sugiere que es posible que haya introgresiones genéticas entre las diferentes especies de Trichoderma, lo cual en algunos casos les permite compartir gran parte de la información genética. En consecuencia, la caracterización morfológica a través de claves taxonómicas que permiten diferenciar las especies no siempre se asocia con grandes diferencias en el genoma de las mismas, pues existen regiones en el genoma que pueden ser compartidas y que no codifican para la expresión o manifestación fenotípica de las estructuras que permiten definir a una especie.

Dentro del género Trichoderma spp. se presenta una gran diversidad intraespecífica (Bissett, 1991) y ésta viene establecida por las diferencias entre las distintas circunstancias donde se desarrollaron los aislamientos, contrastes entre las áreas geográficas donde se encuentran y las fuentes de inóculo muestreadas, características propias de cada individuo y la forma cómo se reproducen (Kredics et al., 2003; 2006).

Cabe mencionar que tradicionalmente, la caracterización y clasificación de microorganismos se ha logrado mediante el uso de descriptores que implican la comparación del material genético basada en fenotipos visibles (forma, tamaño, coloración) y aunque estas características clásicas son todavía muy útiles, la eficiencia de identificación puede reducirse debido a la naturaleza subjetiva que implica hacer observaciones que dependen netamente de la sensibilidad del observador y por tanto puede abarcar un porcentaje de error.

De acuerdo con lo anterior, es necesario observar que a pesar de la presencia de aislamientos de $T$. harzianum en los tres agrupamientos identificados, el hecho de que el segundo agrupamiento solo este integrado por $T$. harzianum en donde se encuentran ubicados el 62,5\% de los aislamientos de esta especie, sugiere que en los marcadores RAPDs utilizados existen bandas que en una alta proporción pueden caracterizar a los aislamientos de T. harzianum.

\section{CONCLUSIONES}

La diversidad genética observada para el género Trichoderma spp. fue mayor dentro de las poblaciones de aislamientos identificadas por su origen geográfico como Ipiales, Pupiales y Gualmatán y menor entre ellas. T. harzianum mostró la mayor variabilidad genética al estar presente en los tres agrupamientos del dendrograma.

\section{AGRADECIMIENTOS}

Los autores manifiesta su agradecimiento a Colciencias por la financiación del proyecto, a la Universidad de Nariño por su apoyo logístico, al Grupo de Investigación en Cultivos Andinos (GRICAND) por su apoyo en las actividades de laboratorio, a los docentes Daniel Marino Rodríguez y Luis Alfredo Molina, al Ingeniero David Álvarez, a la bióloga Diana Burbano.

\section{REFERENCIAS BIBLIOGRÁFICAS}

ALABOUVETTE, C. y STEINBERG, C. 2006. The soil as a reservoir for antagonists to plant diseases. pp. 123-144. In: Eilenberg, J. and Hokkanen, H.M.T., An Ecological and Societal Approach to Biological Control, Springer, Netherlands.

BISSETT, J. 1991. A revision of the genus Trichoderma. II. Infrageneric classification. Canadian Journal of Botany. 69(11):2357 - 2372.

CARLILE, M. y WATKINSON, S. 1996. The fungi. First edition. N.Y. Academic Press. London. 608 p.

CHAVERRI, P., CASTLEBURY, L., OVERTON, B. y SAMUELS, G. 2003. Hypocrea/Trichoderma: species with conidiophore elongations and green conidia. Mycologia. 95(6):1100 - 1140. 
GONZÁLEZ, S, J., MARURI, G. y GONZÁLEZ, A. 2005. Evaluación de diferentes concentraciones de Trichoderma contra Fusarium oxysporum agente causal de la pudrición de plántulas de papaya (Carica papaya L.) en Tuxpan, Veracruz, México. Revista UDO Agrícola. 5(1):45 - 47.

GRIFFITH, G. y SHAW, D. 1998. Polymorphisms in Phytophthora infestans: Four Mitochondrial Haplotypes Are Detected after PCR Amplification of ADN from Pure Cultures or from Host Lesions. Applied and Environmental Microbiology. 64(10):4007 - 4014.

HARMAN, G. 2006. Overview of mechanisms and uses of Trichoderma spp. Phytopathology. 96:190 - 194.

KREDICS, L., ANTAL, Z., DÓCZI, I., MANCZINGER, L., KEVEI F. y NAGY. 2003. Clinical importance of the genus Trichoderma. Acta Microbiologica et Inmunologica Hungarica. 50(2):105 - 117.

KREDICS, L., HATVANI, L., ANTAL, Z., MANCZINGE, L., DRUZHININA, I., KUBICEK, C., SZEKERES, A., NAGY, A., VÁGVÖLGYI, C. y NAGY, E. 2006. Green mould disease of oyster mushroom in Hungary and Transylvania. Acta Microbiologica Immunologica et Hungarica. 5(3):306 - 307

KULLNIG, C., KRUPICA, T., WOO, S., MACH, R., REY, M., BENITEZ, T., LORITO, M. y KUBICEK. C. P. 2001. Confusion abounds over identities of Trichoderma biocontrol isolates. Mycological Research. 10(5):769 -772 .

LARDNER, P., JHNSTON, K., PLUMER y PERSON. 1999. Morphological and molecular analysis of Colletotrichumacutatum sensulato. Mycological Research. 103(3):275 - 285.

LUNA, M., FLORES, M. y PONCE, N. 2003. Caracterización molecular de aislados de Sclerotium cepivorum mediante análisis del polimorfismo de los fragmentos amplificados al azar. Elementos. 49:53 - 59.

REY, M., DELGADO, J., RINCÓN, A., LIMÓN, M. y BENÍTEZ, T. 2000. Mejora de cepas de Trichoderma para su empleo como biofungicidas. Revista Iberoamericana de Micología. 17:531 - 536.
SAMUELS, G. 2006. Trichoderma: systematic, the sexual state, and ecology. Phytopathology. 96:195 - 206.

SÁNCHEZ, V., REBOLLEDO, 0., PICASO, R., CÁRDENAS, E., CÓRDOVA, J., GONZÁLEZ, O. y SAMUELS, G. 2008. In vitro antagonism of Thielaviopsisparadoxaby Trichodermalongibrachiatum. Mycopathologia. 163:49 - 58.

VERMA, M., BRAR, S., TYAG, R., SURAMPALLI, R. y VALERO, J. 2007. Review: Antagonistic fungi, Trichoderma spp.: Panoply of biological control. Biochemical Engineering Journal. 3(7):1 - 20.

WILLIAMS, G., KUBELIK, R., LIVAK, J., RAFALSKI, J., ANTONI, y TINGEY, S. V. 1990. DNA polymorphisms amplified by arbitrary primers are useful as genetic markers. Nucleic Acids Research. 18(22):6531.

WOO, S., SCALA, F., RUOCCO, M. y LORITO, M. 2006. The molecular biology of the interactions between Trichoderma spp, pathogenic fungi, and plants. Phytopathology. 96:181 - 185. 